\title{
Análisis multitemporal en ciudades medias con mapas de la percepción. Albacete: 1993-2016
}

\author{
Juan Antonio García González $\bowtie$ \\ Recibido: 11/03/2017 | Aceptado: 09/12/2017
}

\begin{abstract}
Resumen
Los cambios acontecidos en las ciudades medias españolas en los últimos 25 años son manifiestos. El urbanismo desaforado ha modificado su tamaño, morfología y estructura. A la par, el importante desarrollo económico, social y tecnológico de España ha transformado la forma de relacionarnos y entender el entorno urbano. Estos cambios afectan tanto al objeto de estudio como al sujeto: la ciudad y sus ciudadanos. Habitualmente las investigaciones sobre cambios han estado centradas en el primero, relegando a un segundo plano el cambio en la percepción que tienen de la ciudad sus habitantes. El artículo examina las posibilidades metodológicas de realizar estudios multitemporales a partir de mapas cognitivos. Se compara un estudio de geografía de la percepción publicado en 1993 sobre la ciudad de Albacete con otro realizado para esta investigación. Se aprecian cambios sustanciales tanto en la cantidad de elementos percibidos como en la idea de ciudad que se tiene.
\end{abstract}

Palabras clave: mapas perceptuales; estudio cualitativo multitemporal; ciudades medias; Albacete

\section{Abstract \\ Multitemporal analysis in medium cities with maps of perception. Albacete: 1993- 2016}

Changes are evident in Spanish medium-sized cities over the last 25 years. Urbanism has changed its size, morphology and structure. At the same time, the important economic growth and technological development of Spain have transformed the way to connect and understand the urban atmosphere. These changes affect the object and the subject of study: city and citizens. Research has usually been centered on the first one, leaving to the background the perception of the city. The article examines the methodological possibilities of multitemporal studies with mental maps. A study of cognition geography about city of Albacete realized in 1993 is compared to another one carried out for this investigation. There are substantial changes in the number of elements perceived and the idea of the city that one has.

Keywords: cognition maps; qualitative multitemporal study; Medium-sized cities; Albacete.

\footnotetext{
1. Este artículo ha sido posible gracias a la concesión del proyecto CSO2015-63970-R (MINECO/FEDER, UE) financiado por el Ministerio de Economía y Competitividad y que lleva por título «Dinámicas de urbanización y políticas urbanísticas en ciudades medias interiores. De expansión y dispersión a reformulación: ¿hacia un urbanismo más urbano?

2. Universidad de Castilla-La Mancha, Facultad de Humanidades de Albacete. JuanAntonio.Garcia@uclm.es
} 


\section{Résumé}

\section{Analyse multitemporelle dans les villes moyennes avec des cartes de perception.} Albacete: 1993-2016

Les changements survenus dans les villes moyennes espagnoles au cours des 25 dernières années sont manifestes. L'urbanisme tapageuse a modifié sa taille, la morphologie et la structure. Au même temps, le développement économique, social et technologique importante de l'Espagne a transformé la façon dont nous rapportons et comprennons l'environnement urbain. Ces changements affectent tant du l'object comme le sujet de létude: la ville et ses citoyens. Habituellement des enquêtes se sont concentrées sur la première, reléguant à l'arrière-plan du changement dans la perception des habitants de la ville. Larticle examine les possibilités méthodologiques pour réaliser des études multitemporelles de cartes mentales. Une étude de la géographie de la perception en 1993 pour la ville d'Albacete avec un autre fait exprès pour cette recherche est comparée. Il y a des changements substantiels à la fois dans le nombre d’éléments perçus et dans l'idée de la ville que l'on a.

Mots-clé: cartes perceptuelles; multitemporelle étude qualitative; les villes moyennes; Albacete.

\section{Introducción}

La trasformación de la sociedad española en el último cuarto de siglo es evidente en infinidad de aspectos. El cambio en las ciudades ha sido espectacular. La población española mantiene la tendencia de convertirse en más urbana que rural. El ritmo ha ido variando, pero la directriz se ha mantenido en el mismo sentido. Las ciudades han crecido en población a la par que en servicios, equipamientos e infraestructuras. Al tiempo, las zonas rurales se han ido despoblando. Este trasvase de población, unido al aumento demográfico, bien por crecimiento natural bien por insumo de inmigración exterior, al crecimiento económico, al fácil acceso al crédito y otra serie de factores, han provocado una importante progresión en el tamaño de las áreas urbanas. En el último cuarto de siglo, ha habido un desaforado aumento de las áreas urbanas especialmente en la denominada década prodigiosa (1997-2007) (Burriel, 2008). El efecto ha sido ostensible en las grandes metrópolis afectando a entornos suburbanos con la aparición de nuevas unidades urbanas vinculadas a la gran metrópoli, pero también son palpables en las denominadas ciudades medias. (Andrés, 2008; López, 2016).

Además de los cambios en tamaño e infraestructuras urbanas, han transformado la forma que tenemos de desplazarnos, de conocer y entender la ciudad. Si manifiestas son las variaciones en el objeto de la investigación, no lo han sido menos las acontecidas en los sujetos de la investigación. Desde la consolidación de una joven democracia, a la incorporación de hecho al proyecto europeo, este país ha alcanzado una espectacular metamorfosis en su territorio, pero también en los hábitos y costumbres de sus ciudadanos. Nuestra forma de movernos, comunicarnos y relacionarnos ha variado sustancialmente. La revolución tecnológica ha irrumpido en nuestras vidas (Roth, 2013; O'Reilly, 2005). Ha sido especialmente significativa en este último cuarto de siglo. La posibilidad de tener potentes dispositivos, a precios asequibles y con conexión a internet ha democratizado el acceso a las Tecnologías de la Información Geográfica (TIG). En la actualidad, la inmensa mayoría de la población dispone de una ingente cantidad de información espacial. Los dispositivos con tecnología de geolocalización se encuentran en nuestros coches y en infini- 
dad de herramientas insertadas en nuestros teléfonos inteligentes. Es evidente que estos cambios han variado nuestra forma de comprender y percibir el territorio.

Ambos elementos externos e internos, asociados al objeto y sujeto de estudio, han transformado la relación ciudad-ciudadano. Es claro el crecimiento en la ciudad, pero también en la percepción que tienen los ciudadanos de ella. Han sido diversas las investigaciones sobre las mutaciones en la fisonomía de las ciudades con análisis estadísticos y cartográficos. Sin embargo, no han sido tan prolijos los estudios sobre los cambios de percepción del crecimiento urbano. Las encuestas han ido mostrando las variaciones de opinión de los ciudadanos. Sin embargo, no se conocen hasta la fecha estudios multitemporales sobre la percepción de las ciudades con mapas cognitivos.

Desde que en 1960 se publicó The image of the city por Kevin Lynch, han sido muy diversas las investigaciones referidas a esta metodología, aplicada a diferentes lugares, con múltiples propósitos y a variados grupos sociales. Muchas de ellas han aportado una visión única de la percepción que tiene un determinado grupo de ciudadanos sobre su entorno urbano inmediato y la interacción entre ambos. Estos estudios de caso, interesantes en sí mismos, han adolecido de una falta de sistematización. Son análisis difícilmente comparables entre ellos. Resulta complejo además extrapolar sus conclusiones, bien por las diferencias estructurales de las áreas de estudio, bien por la falta de homogeneización en la muestra. La falta de uniformidad en las fuentes entorpece la posibilidad de establecer puentes entre realidades diferentes. Esta dificultad se acrecienta cuando se trata de análisis de percepciones no tangibles y que en multitud de ocasiones son tan importantes como la morfología y estructura de la ciudad.

La presente investigación explora las posibilidades del estudio de la geografía de la percepción de forma multitemporal. Analiza las ventajas e inconvenientes de trabajar con mapas cognitivos de una misma ciudad en dos fechas con un intervalo de veinticinco años. Busca establecer comparaciones entre la percepción de la ciudad de Albacete realizada por estudiantes de la escuela de Magisterio de la Universidad de Castilla-La Mancha en 1993 (Fernández y García, 1993), y la concepción mental que tienen hoy en día los estudiantes de la facultad de Humanidades de la misma universidad. Se ha repetido el estudio y se ha analizado siguiendo la metodología utilizada entonces. El artículo muestra los posibles cambios de la percepción urbana de la ciudad de Albacete a través de las diferentes representaciones espaciales de los universitarios de entonces y ahora. Se han tomado en consideración los cambios morfológicos de la ciudad y se han comparado las percepciones en uno y otro caso. Los mapas mentales, o cognitivos estrictamente dicho, pueden suponer una forma de análisis multitemporal de cambios, tanto morfológicos como de percepción de la ciudad (Taylor, 2007 en Gieseking, 2013:714).

\subsection{Los mapas cognitivos y la geografía de la percepción}

El ser humano tiene la capacidad de convertir la información del mundo exterior en una interpretación personal a través de sus sentidos, conocimientos y experiencias previas. Cada individuo cuenta con una cognición propia. Por cognición se asume la «suma de subconjuntos de sensación, percepción, recuerdo, razonamiento, solución de un problema, juicio y evaluación. Incluye procesos varios por los cuales la información visual, lingüística, semántica y comportamental es seleccionada; codificada, reducida, elaborada, almacenada, retransmitida y utilizada.» (Moore y Golledge; 1976). Toda persona, por el simple hecho de desplazarse por la superficie terrestre, tiene una construcción mental de ese lugar. Cauvin en 1984 lo definió como «los espacios cognitivos son espacios «obtenidos», "construidos», después de modificaciones y transfor- 
maciones realizadas por nuestros filtros personales y culturales a partir de los espacios físicos y funcionales» (Escobar, 1991:46).

Esta percepción puede ser representada en un croquis o mapa cognitivo. El psicólogo Edward Tolman fue el primero en definir formalmente los mapas cognitivos. El «premapa» o esbozo mental de un territorio sirve para relacionarnos con el territorio en nuestros movimientos cotidianos a partir de experiencias y bagajes. Muestra como los humanos conciben el espacio y refleja esos pensamientos en sus comportamientos diarios. Los mapas mentales combinan las emociones con la memoria de la cotidianidad. Existe un precedente en el geógrafo C.C. Trowbidge (1913) con referencias al concepto de mapa imaginario o la pregunta de Koffka sobre si ¿vivimos todos en la misma ciudad? (Bosque et al., 1992:45).

Los mapas cognitivos son también denominados mapas mentales (De Castro, 1999). Estos términos suelen ser utilizados indistintamente. Ambos son construcciones mentales a partir de nuestras estructuras previas, conocimientos, experiencias y creencias. Los mapas mentales, en su sentido estricto, no tienen por qué representar elementos territoriales, aunque si espacializan ideas interrelacionadas. El mapa cognitivo tiene una clara vocación espacial y se asocia más al tradicional croquis (De Castro,1997). Supone una importante aportación metodológica a la geografía de la percepción, al ser una proyección psicológica de la comprensión del espacio (Villena, 2012, Hernández, 2009). Esa comprensión individual del espacio es también una proyección de la concepción de grupo: «homomorphic mapping» (Gould, y White, 1974:52). Es la imagen perceptual de la ciudad en un instante determinado de un grupo de ciudadanos con unas características, inquietudes y relaciones con su entorno cercano similares, pero al mismo tiempo con sus propias y únicas percepciones. Las formas de recabar información con este tipo de mapas y su utilización son diversas. Por ejemplo, se puede partir de un mapa mudo con la posibilidad de etiquetarlo y analizar dichas etiquetas (Gould y White, 1974). Otra opción es dibujarlo y usarlo como punto de partida en un grupo de discusión (Dennis, 2010 en Gieseking, 2013:714).

La geografía de la percepción analiza el espacio geográfico a través del tamiz de la imagen abstracta que tienen los usuarios de la misma con mapas mentales. La interpretación de esas abstracciones permite conocer la importancia o minusvaloración que hace un colectivo de personas sobre lugares comunes a todos ellos. Enseña los claroscuros de un espacio concreto percibido a través de las vivencias de sus ciudadanos. En una de las múltiples derivadas de la geografía nos acercamos a los terrenos de la psique cual interpretación de los sueños en el psicoanálisis. (Carreiras, 1986). Se trata de una metodología eminentemente subjetiva donde la interdisciplinariedad debiera ser un elemento central en este tipo de trabajos (Estébanez, 1981; Morales, 2015:204). En el caso de la geografía se enmarca dentro del aspecto más humanístico de la geografía y menos cuantitativo.

La diversidad de campos de actuación de la geografía y el amplio espectro de metodologías que utiliza para llegar a sus fines, provoca y mantiene una continua dialéctica en el seno de la disciplina, sujeta a los vaivenes epistemológicos del momento. Desde los contenidos de la geografía física más próximos a las ciencias naturales hasta los entornos más culturales y humanísticos, la geografía se mueve por un crisol de temáticas y metodologías para analizar el espacio. Los propios términos geografía y espacio son conceptos polisémicos con múltiples acepciones, que han servido de acicate a la diversificación de estudios geográficos, así como a incrementar la dificultad de definir con concreción el objeto de estudio de la geografía (Dollfus, 1978). El territorio es variable, cambiante, medible y representable. Muchos de los estudios buscan una posición externa al objeto de estudio en aras de una interpretación más aséptica y supuestamente imparcial. Sin 
embargo, hay otras corrientes que consideran tan importante el objeto como el sujeto de estudio. Todos los postulados tienen en común su preocupación por el análisis del espacio en sus múltiples acepciones y derivadas desde el geométrico y euclidiano, pero también el vivido y cognitivo. Diversos espacios conviven en una misma realidad, pero sus estudios suelen acometerse de forma separada. Son varias las corrientes de pensamiento geográfico, como la geografía de la percepción, que se aproximan a postulados más subjetivos justificando un cambio en la posición del observador como parte del objeto de estudio. El geógrafo es parte de la ecúmene.

La geografía de la percepción y del comportamiento surge en los países anglosajones en la segunda mitad del siglo pasado. Es, en parte, la respuesta a la prevalencia de la geografía cuantitativa donde impera el rigor y la exactitud de la geometría cartográfica menospreciando la importancia de las relaciones topológicas y de las representaciones perceptuales (De Castro y Bosque, 1993: 87). El paradigma positivista quizás haya acercado a la disciplina a esos anhelos históricos de regirse por el método científico de las ciencias naturales, pero, sin embargo, no ha resuelto el aumento de reconocimiento de la disciplina por la sociedad. Se sigue poniendo énfasis en hábitos y rutinas de trabajo que relegan el quehacer cotidiano, útil y perceptual de la geografía. La geografía de la percepción y del comportamiento supone una aproximación distinta, subjetiva e individualizada al territorio donde se valora la experiencia y el conocimiento que tiene cada individuo del objeto de estudio. Mira al espacio desde la subjetividad del individuo permitiendo explorar el conocimiento que tienen sus ciudadanos de la ciudad, así como su relación con la misma (Estébanez, 1979:5; Bosque et al., 1992:16; Somoza, 1995; Ellard, 2016). Es una forma más cercana e intuitiva de comprender el siempre complejo entramado urbano y su forma de percibirlo.

Esta corriente geográfica cuenta con un desarrollo metodológico relativamente reciente. Son significativas las revisiones bibliográficas sobre los cuantiosos documentos referidos al tema (Estébanez, 1979; Zárate et al., 1985; Aragonés, 1988; Boira, 1992; Bosque el al.,1992; Reques, 1992; Vara, 2008; 2010; 2010b). Y, son varios los altibajos en la consolidación de la corriente geográfica como línea de trabajo, habiéndose diversificado las metodologías y aplicado a multitud de lugares. Todos ellos coinciden en situar su origen en la publicación de «La imagen de la ciudad» (Lynch, 1960). El profesor Lynch planteaba el reconocimiento de una serie de elementos comunes que determinan la estructura mental que tienen las personas de las ciudades americanas de Jersey, Boston y Los Ángeles. Lynch fue un urbanista que arrancó desde postulados sociológicos para, años más tarde en la evolución de sus estudios, trasladarse hacia conceptualizaciones más geográficas en la buena forma de la ciudad (Lynch, 1981). Al hilo de esta publicación, aparece un año más tarde el primer estudio hecho desde la geografía: «Geography, experience and imagination. Towards a geographical epistemology» (Lowenthal, 1961). En la década de los 70 se incrementaron los estudios con Metton en 1971 y Cole en 1972 (Vara, 2008 372). Destaca significativamente el crecimiento del enfoque fenomenológico estudiando los sentimientos hacia lugares de Yi Fu Tuan (Tuan, 1974) o la mejora de la sistematización de los mapas mentales con Appleyard en sus estudios en la Guayana (Appleyard, 1976). Mientras unos estudios trataban de abrir el espectro conceptual y metodológico de esta geografía, otras investigaciones simplificaban la clasificación de Lynch abstrayéndola a tres elementos: puntos líneas y superficies (Pocock y Hudson, 1978 en Morales, 2015:206). Representa un acercamiento de los postulados cualitativos a sistematizaciones más cuantitativas propias de los Sistemas de Información Geográfica (SIG). Esta aproximación, y otras posteriores, no han solucionado la posibilidad de utilizar de forma continua modelos matemáticos a partir de datos perceptuales. No obstante, poco a poco han ido aumentando las técnicas cuantitativas con análisis multivariado, conglomerados, análisis de correspondencias,... (Aragonés, 1988; Buzai, 2011). 
El incesante crecimiento de las TIG ha desplazado a un segundo plano aquellas corrientes apoyadas en la información cualitativa y en la subjetividad. El espectacular desarrollo de los datos georreferenciados ha abierto un vasto campo de posibilidades analíticas, facilitadas por los automatismos de las operaciones de los SIG. Estas herramientas, cada vez más intuitivas han desvinculado relación entre el volumen de datos trabajados y el tiempo utilizado para su análisis. Este cambio trascendental no ha ocurrido en los estudios con mapas perceptuales donde la individualidad y lo analógico de los datos primarios mantienen lo artesano de su sistematización. Dentro de los estudios de la geografía de la percepción, las tecnologías han abierto nuevas posibilidades en el estudio del comportamiento. Se trata de estudios relacionados con el comportamiento de los individuos más que con la percepción que tienen del territorio. Al albor del concepto de los bigdata surgen formas de analizar la conducta del ser humano sobre el territorio. Aun así, todavía resulta complejo analizar la percepción y la idea preconcebida que se tiene del mismo. Se analizan datos sobre hechos ya acontecidos y no una visión o percepción previa de la ciudad que nos pueda llevar a una interpretación de la misma, distinta del análisis de movilidad de los individuos en unas determinadas coordenadas espacio-temporales.

En la década de los 70 aparecieron los estudios sobre Geografía de la percepción en España. El pionero en abordar la temática fue el profesor Capel «Percepción del medio y comportamiento geográfico» (Capel, 1973). Fue el prólogo de lo que años más tarde vendría. El primer estudio, propiamente dicho apareció en 1978 de la mano de Brunete y Segui sobre la ciudad de Palma de Mallorca (Vara, 2008: 376). Un año más tarde Estébanez publicó «Consideraciones sobre la geografía de la percepción». Al tiempo salía a la luz "La percepción del espacio urbano: conceptos, método de estudio y su utilización en la investigación urbanística» (Bailly, 1989) procedente de las influencias francesas tan presentes en la geografía española. Desde entonces, han sido variados los estudios en diversas ciudades, con diferentes grupos sociales y con múltiples propósitos. El carácter de Albacete se aleja de estudios como pueden ser Segovia (García y Bosque, 1989), Granada (Bosque, 1991), Vigo (Souto y Boira, 1991) o Almería (Fernández y Asenjo, 1998). Ciudades donde relieve, hidrografía, línea de costa u otros accidentes naturales sirven de elementos idiosincrásicos de la ciudad. Albacete se aproxima más, tanto por relieve como por concepto de ciudad media, a estudios como el de Yecla (Morales, 2012), Ciudad Real (Muñoz y Rodríguez, 2015) o Novelda (Villena, 2012).

Esta corriente geográfica contó con no poco detractores desde sus inicios. Múltiples críticas han acompañado a su desarrollo. La sistematización de resultados, elaboración de conclusiones y posibles generalizaciones resultan complejas. Ya Glaser y Strauss en 1967 hablaron de la dificultad para su evaluación con el método de comparación continua (Hernández; 2006). A su vez, otras de las grandes adversidades de este tipo de estudios, radican en la complejidad para extrapolar datos, y en la dificultad de establecer relaciones tanto espaciales como temporales. Es complejo dar continuidad, ya que cada investigación se circunscribe a su área de estudio y a su muestra, teniendo únicamente en común la metodología de análisis. Muchas de las actividades son ejercicios aislados e inconexos (Estébanez, 1981). En ocasiones, varia ya no sólo el tamaño de la muestra sino también la forma en la que se obtienen dichos datos. Resulta complejo elaborar generalizaciones extrapolables a otros lugares y estudios que permitan avanzar en el corpus de la disciplina. Es altamente difícil repetir las condiciones del experimento asumiendo la «no individualidad» del objeto de estudio. Los propios Boira, Souto y Reques (1994) hablan de la falta de criterios a la hora de aplicar esta metodología. Aun así, estos mismos autores lo valoran positivamente como herramienta para conocer la imagen subjetiva de la ciudad y la interacción del sujeto con el objeto de estudio (Reques, 2006). La dificultad de ajuste del método con el método científico de las 
ciencias naturales, la tabulación analógica de los datos y la dificultad de sistematización pueden ser algunos de las cuestiones que han retraído a los investigadores a profundizar en esta línea de trabajo. Por el contrario, resulta sorprendente la profusión de estudios que se han llevado a cabo y cuyos resultados todos valoran como altamente explicativos y que en muchas ocasiones las frías estadísticas no son capaces de mostrar.

\section{Metodología}

El proceso metodológico seguido se estructura en tres grandes apartados. En primer lugar, la obtención de los datos y el posterior tratamiento de ambas fechas con el fin de disponer de información lo más homogénea y comparable posible. Seguidamente se analiza la tipología de mapas y el área representado (Appleyard, 1976) para pasar a un análisis más detallado (Lynch, 1960). Finalmente, y a modo de resumen, se comparan las imágenes sintéticas resultantes de la ciudad percibida en 1993 y 2016 obtenidas tras el volcado de los datos tabulados al SIG.

\subsection{Levantamiento de los datos}

En 1993 se utilizaron 63 mapas mentales elaborados por estudiantes de la Escuela Universitaria de profesorado de EGB matriculados en los cursos 90-91 y 91-92, en segundo año de la especialidad de preescolar. Más de las tres cuartas partes $(77,8 \%)$ de los estudiantes encuestados se encontraban en edades entre 20 y 22 años y el 94\% eran mujeres. A lo largo del año 2016 se recogieron un total de 75 mapas en cinco muestras. Todas fueron realizadas por estudiantes de los diferentes cursos que se imparten en la Facultad de Humanidades de Albacete (ver tabla 1).

Cuadro 1. Estructura de la muestra de 2016

\begin{tabular}{|c|c|c|}
\hline GRUPO & FECHA & MAPAS \\
\hline PIRG (*) 16 & ene-16 & 18 \\
\hline SARAMG 16 & $a b r-16$ & 12 \\
\hline PIRG 15 & may-15 & 16 \\
\hline MS 16 & ene-16 & 17 \\
\hline \multirow[t]{2}{*}{ GEOYSOC16 } & $a b r-16$ & 12 \\
\hline & TOTAL & 75 \\
\hline \multicolumn{3}{|c|}{$\begin{array}{l}\text { * Las siglas que aparecen hacen referencia a los estudios y asignaturas donde se tomaron } \\
\text { las muestras: PIRG } 16 \text { (Percepción e Interpretación de la Realidad Geográfica, 2016); } \\
\text { SARAMG } 16 \text { (Curso de la Universidad de Mayores José Saramago, 2016); PIRG 15 } \\
\text { (Percepción e Interpretación de la Realidad Geográfica, 2015); MS } 16 \text { (Master de Educación } \\
\text { Secundaria, 2016); GEOYSOC16 (Geografía y Sociedad, 2016). }\end{array}$} \\
\hline
\end{tabular}

Se procuró seguir el mismo patrón de 1993 para la toma de datos. Los conocimientos previos de los encuestados sobre la geografía de la percepción y la metodología de Lynch eran escasos o nulos. Se facilitó un papel en blanco tamaño Din-A3 a cada encuestado. La disponibilidad de papel de esas dimensiones permite una reflexión mayor por parte del encuestado. El tamaño del papel redunda en la cantidad de información aportada, aunque desde luego no es una afirmación suficientemente estudiada (Kitchin y Freundschuh, 2000 en Gieseking, 2013:715). En otros estudios previos se utilizó también este tamaño de papel al igual que el tiempo disponible (Bosque el al., 1992:51; García, 2015). 
Los estudiantes dispusieron de 20 minutos para la elaboración del mapa perceptual. A medida que aumenta el tiempo para la realización del ejercicio, la imagen es más elaborada acercándose más al diseño de una imagen preconcebida de mapa que a la cognición personal que se tiene de la ciudad (Gieseking, 2013:715). Se pretendía conseguir la imagen espontanea que tienen de la ciudad y no tanto una visión reflexiva. No contaron con ayuda suplementaria, más allá de las indicaciones sobre la importancia y el valor de la individualidad de su representación cognitiva. Se prohibió la posibilidad de utilizar elementos externos como visualizar un mapa desde el teléfono móvil o el ordenador. Con posterioridad se les informó sobre las posibilidades que otorgan estas cartografías, que a priori, ellos consideran como poco valiosas. Se reforzó la importancia de su percepción con sus vacíos y silencios frente al mapa formal. En alguna ocasión aparecen encuestados reacios a realizar el mapa aduciendo falta de confianza sobre lo que plasman en el papel. Estas reacciones tienen que ver con la ansiedad de dibujar en público (Winnicott, 1992 en Gieseking, 2013:719). No son pocas las personas que cuando les pides un mapa de la ciudad, lo primero que comentan es que ellos no saben dibujar. El dibujo es una destreza poco trabajada para la creación de croquis y elementos de percepción territorial que ayuden a la interpretación y comprensión del territorio (Vara, 2008:379). En el aprendizaje formal del individuo se focalizan las destrezas en la lectoescritura dejando de lado otras capacidades que resultan fundamentales para el mundo en el que vivimos y que nos llevan a un déficit posterior (Souto, 1994). La escasez de destrezas espaciales merma la relación del individuo con el territorio. Para salvar algunas de estas reticencias, se permitió que aquellas personas que no lo estimaran oportuno, no entregasen su mapa.

\subsection{Tabulado de los datos}

Una vez recogidos los mapas se procedió a su tabulación en una hoja Excel según los criterios empleados en 1993 (Fernández y García, 1993; Rodwin et al. 1969 en Bosque et al., 1992:53 y Lynch, 1960). A partir de estos postulados teórico-metodológicos se han desgranado los diferentes elementos representados en los mapas cognitivos. No se ha podido recuperar el material original de 1993 para haberlo tabulado nuevamente, con los mismos criterios. Esto genera una dificultad añadida al comparar datos primarios de 2016 con información ya tratada y seleccionada de 1993. Es evidente que el estudio pudiera haber sido más preciso de haber dispuesto de las fuentes primarias originales.

La organización y tabulado de los datos partió de lo general con una caracterización de la tipología de los mapas para pasar a un análisis de detalle según los elementos estructurantes de la imagen urbana descritos por Lynch. En un primer acercamiento, se comparó la tipología de los mapas dibujados por los participantes. La libertad otorgada al realizar los croquis o mapas mentales hace que el resultado obtenido con fuentes primarias sea mucho más diverso que con otras formas de obtención de información como pueden ser las encuestas. La catalogación de los mapas realizados es un proceso altamente subjetivo al tratar de encajar todos y cada uno de los mapas dibujados en una serie de ítems predefinidos. Según la metodología se llegan a discernir ocho tipologías de mapas cognitivos presentados en dos grandes grupos: secuenciales conformado por fragmentados, en cadena, en circuito e hilados o en malla; y espaciales compuesto por mapas dispersos, en mosaico, relacionados y en red (Rodwin et al. en Bosque el al., 1992:53). Conviene recordar que el proceso de asignación a uno u otro tipo se ha hecho con 25 años de diferencia y por personas diferentes, lo que puede hacer variar el criterio de asignación de uno a otro. Esta dificultad es permanente en todo el estudio al no disponer de los mapas originales. Por 
ello, nos limitaremos a comparar la tipología entre secuencial y espacial obviando entrar a valorar la catalogación detallada en las ocho categorías.

Lynch distinguió en su imagen de la ciudad hitos, nodos, sendas, bordes y barrios (Lynch, 1960). Estos elementos son el objeto de análisis de detalle. Los hitos son puntos con una ubicación singular que le permiten ser visto y reconocido. Estos elementos pueden ser únicamente visuales e incluso no accesibles como pudiera ser un castillo o iglesia. Los hitos son las puntadas de costura entre la realidad y la percepción. Cual puntos de control en la georreferenciación cognitiva del individuo con el territorio, permiten estructurar, primeramente, sendas y nodos, y de forma complementaria barrios y límites. Los nodos son también puntos de anclaje conceptual de la ciudad. Son conexiones estratégicas de las vías o sendas. El nodo suele tener un sentido más topológico que geométrico. Son también puntos de ruptura e intercambio de transporte: estaciones, intercambiadores,...

Por su parte, las sendas son los caminos que permiten introducirnos y reconocer la ciudad desde su interior, con una alta capacidad de ser imaginadas. El tránsito cotidiano por las sendas nos lleva de nodo a nodo, formándose en nuestra mente una red. Son vías por las que se transita y recorre la ciudad. Son el itinerario por el que adquirimos la información. No tienen por qué ser las más importantes, aunque suele existir una correlación entre su funcionalidad y el valor que cada uno de los encuestados les otorga.

Los límites o bordes, al igual que las sendas, necesitan una cierta continuidad y linealidad en su extensión para su definición. Deben contar con un importante reconocimiento sobre el terreno que lo conviertan en una barrera mental e incluso física en ocasiones. Los bordes son elementos que definen el límite de la ciudad, lo que el ciudadano considera urbe y lo que no. También representan rupturas internas de la propia aglomeración urbana. En algunos casos el límite aparece difuso, simplemente se deja de dibujar una parte de la ciudad. Acontece fundamentalmente en los mapas parciales y suele producirse por desconocimiento de esa zona. Otras veces se presentan casos donde el encuestado dibuja límites que determinan y condicionan el resto del croquis.

Finalmente, los barrios son áreas urbanas que cuentan con una homogeneidad intrínseca en plano, tipología constructiva, historia o simplemente localización. La concepción de barrio suele venir definida más como topónimo que organiza diferentes zonas del mapa que como suma de polígonos conectados y delimitados. Definir el borde de la ciudad es complejo, más aún los límites y bordes de cada uno de los barrios. El polígono es el elemento geométrico más complejo. En la abstracción mental del espacio, el polígono implica la definición de límites de una superficie. La ciudad se aprende transitando por las sendas y se memoriza por puntos como nodos e hitos. Transitar la ciudad no implica memorizar y organizar los espacios. La percepción de la ciudad es más puntual que lineal y desde luego que areal.

\subsection{Cartografía comparada}

La metodología empleada finaliza con la representación cartográfica de los elementos tabulados. La ciudad de Albacete se presenta en cartografías con ortofotos de entonces y ahora relacionando los cambios de su morfología con los cambios en la percepción de la misma por los estudiantes. No se disponía de cartografía urbana en formato vectorial de 1993 y por ello se ha optado por representar el resultado sobre una imagen aérea de la ciudad de 1997 facilitada por el Centro Cartográfico de Castilla-La Mancha de la Junta de Comunidades de Castilla-La Mancha (Mapa 
2). Es la imagen disponible que más se aproxima a la fecha del estudio. Se consultó en la Gerencia Municipal de Urbanismo del Ayuntamiento del Albacete el mapa en papel a escala 1:1000 con fecha de mayo de 1992. Esta cartografía se realizó a partir de un levantamiento fotogramétrico de un vuelo con una escala aproximada 1:5000 de febrero de 1992. Son fotogramas que no se han podido localizar para la presente investigación. La variación de la ciudad desde 1992 a 1997 es escasa. Los cambios se manifiestan fundamentalmente en una densificación del interior de la circunvalación y no en su perímetro. Se ha incluido también la ortofoto actual (PNOA máxima actualidad) para que el lector pueda percibir por sí mismo, el crecimiento producido en la ciudad en los últimos 20 años a través de ambas ortofotos (Mapa 1). Los datos de 2016 se han representado sobre la base cartográfica Cartociudad de 2016 del Instituto Geográfico Nacional (Mapa 3). El resultado visual es más legible al utilizar una base cartográfica y no una ortofoto.

\section{4. Área de estudio}

Albacete es una ciudad de tamaño medio ubicada en la meseta sur. Es la más poblada de CastillaLa Mancha con 172.426 en 2016, frente a los 130.093 con que contaba en 1991. Supone el 43,97 de la provincia y el de 8,44 la comunidad autónoma en la actualidad frente al 37,96 y el 7,84 respectivamente de 1991. Su principal característica es que se ubica en una llanura casi perfecta. Su forma compacta, su tamaño medio y su homogénea orografía facilitan el tránsito a pie no necesitando más de una hora para ir de un extremo al otro, en cualquiera de sus direcciones.

Se localiza en el borde oriental de la llanura manchega, rincón conocido como los Llanos de Albacete o históricamente como la Mancha de Montearagón, tal y como aparece reflejado en El Quijote. En Albacete no hay ningún elemento natural reseñable, más allá parques urbanos o periurbanos. No existe ningún curso fluvial permanente o temporal que sirva de referencia lineal a la estructura urbana. La ciudad se asienta sobre un acuífero con surgencias en sus proximidades y que hasta bien entrado el siglo XIX generaba una zona encharcada e insalubre. Esta situación cambió con la creación del canal de María Cristina ofreciendo escorrentía a esta zona endorreica. Este colector se encuentra actualmente soterrado a su paso por la ciudad y pasa desapercibido a muchos de sus ciudadanos. Es un plano prácticamente isotrópico, cual modelo de Von Thünen, y levemente asimétrico en la disposición concéntrica de su trama. Es difícil encontrar una ciudad con tan pocas referencias visuales urbanas determinadas por el medio natural. Además, el orden deliberado de lo construido responde a criterios funcionales y estéticos cautivos de la abstracción (Aguiló, 1999:13). Este orden tiende a minimizar, todavía más, las condiciones naturales del entorno.

El crecimiento de la ciudad en este último cuarto de siglo ha sido espectacular. Se ha producido una consolidación de la ciudad en el interior de la circunvalación. A su vez ha crecido de forma considerable en todas las direcciones al exterior de la misma vía rápida convertida en calle. Especialmente significativos son los desarrollos urbanos en el noreste de la ciudad (zona de Imaginalia, sector 14) en su unión al polígono industrial y al sur de la ciudad (sectores 12 y 19) asociado a la universidad (ver mapa 1). 
Mapa 1. La ciudad de Albacete, 2016

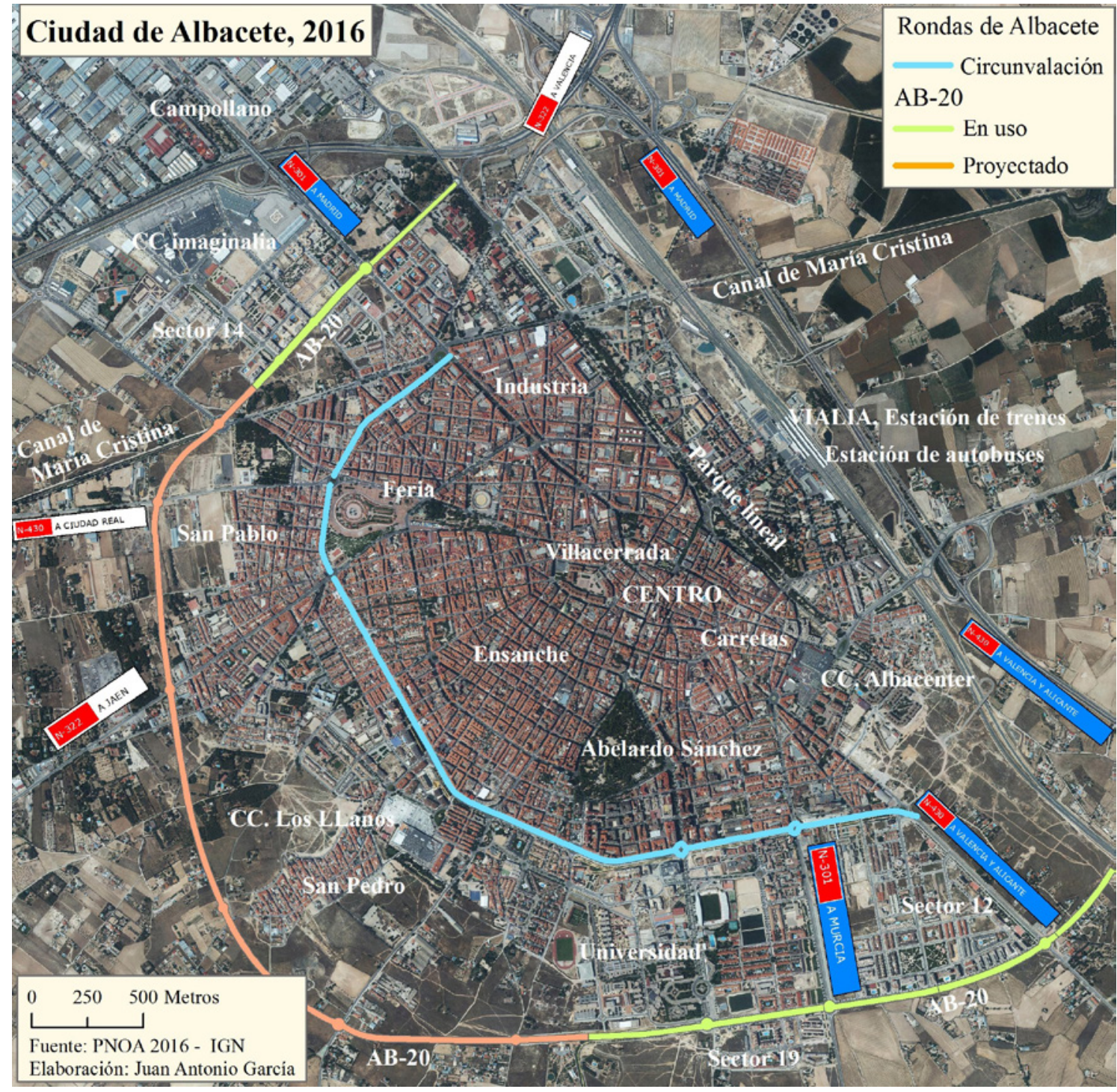

Elaboración propia

\section{Resultados}

Un primer resultado fruto del paso del tiempo es el cambio en el perfil de la muestra. Se ha producido una diversificación de la tipología de estudiantes que conviven a diario en el ambiente universitario, abriéndose la universidad a nuevos perfiles de alumnado. Estudios de grado, master y la denominada Universidad de Mayores José Saramago han permitido conformar la muestra. Es significativo en sí mismo el cambio en edad y sexo de la distribución. En estos últimos 25 años se ha producido una clara consolidación del acceso de nuestra juventud a los estudios superiores y una diversificación de los perfiles. Casi las dos terceras partes $(65,3 \%)$ se encuentran en la horquilla de 18 a 25 años manifestándose un aumento del grupo de mayores (mayores de 56 años) que se aproxima al $20 \%$. Se debe tanto a la aportación de la universidad de mayores, como de personas con cierta edad matriculadas en estudios reglados. La variación respecto al género sigue decantándose hacia las mujeres, pero ha tendido a reducirse la brecha con el 62,7\% de mujeres fruto, en parte, por la variación de estudios donde se realizó la encuesta. 


\subsection{Tipología de mapas}

En referencia a la cantidad de ciudad representada aparecen importantes contrastes. En 1993 la diferencia era abrumadora hacia la representación parcial con un $71,4 \%$ de los casos. En la percepción de 2016, se manifiesta un cambio de tendencia. Más de la mitad de los mapas tienden a representar de forma total la ciudad frente a 46,5 de los casos que lo hacen de forma parcial. Este primer elemento resulta ya muy significativo al mostrar la relación del individuo con el territorio. Es difícil transitar o recorrer partes de la ciudad que uno no tiene en su mapa cognitivo. Es factible aceptar que ha aumentado la movilidad de las personas, pero también es probable que el aumento de información que se tiene sobre la ciudad hoy en día, se consiga sin haberla transitado y a través de dispositivos móviles.

Algo similar ocurre en la tipología de mapas representados. En 1993 abundaban los mapas secuenciales basados en la línea con un 42,9\%. En la muestra actual ese porcentaje asciende a un tercio de los mapas. Por el contrario, en 2016 los mapas espaciales llegan al 65,3\%. Esta diferencia está condicionada por el elevado número de mapas que en 1993 quedaron sin englobar en alguna de las categorías; casi un tercio de los mapas, mientras que en el estudio actual no llega al testimonial uno por ciento de la muestra. En el primer estudio se interpretaron un mayor número de mapas secuenciales frente a los espaciales, por el patrón de respuesta de muchos de los estudiantes. Dominaba un conocimiento parcial con un itinerario lineal. Hoy se aprecia que la forma de representar la ciudad ha variado. Intuimos que uno de los elementos que condiciona este cambio se encuentra en la mayor disponibilidad de información cartográfica en 2016 frente a 1993. La democratización al acceso de información cartográfica con los teléfonos inteligentes y la incorporación de herramientas como Google Maps o redes sociales con herramientas de geolocalización, entre otros ejemplos, han cambiado radicalmente la relación de los estudiantes universitarios con su entorno. Son múltiples los ejemplos donde los jóvenes entran en contacto con el territorio incluso con actividades lúdicas como el geocaching o juegos como el Pokémon go. Esta revolución tecnológica referida a la información georreferenciada ha permitido un mayor conocimiento del territorio. La percepción de la ciudad de Albacete, ya no sólo se hace por su tránsito y devenir diario. Hoy en día, se utilizan herramientas de geolocalización que guían a través de cartografía online para muchos de los recorridos. Este acceso es bien por uso directo nuestro o bien al hacernos llegar localizaciones concretas (ej. geolocalización de WhatsApp). Este cambio de hábito se manifiesta en la percepción que se tiene de la ciudad. El área urbana se dibuja en su conjunto en un mayor número de casos. Se vislumbra un conocimiento del territorio más holístico.

Mientras que en 1993 la línea era el hilo conductor de la representación y predominando los mapas secuenciales; en 2016 domina la superficie y los croquis con prevalencia espacial frente a la lineal. La línea implica direccionalidad mientras que el polígono busca delimitación. La concepción espacial actual es más elaborada que la secuencial de 1993. La mayoría de los mapas secuenciales basaban su conocimiento de la ciudad, al transitar por la misma en su pendular desplazamiento de la vivienda a la universidad. Hoy se mantiene ese tránsito y se apoya con herramientas que permiten obtener información detallada de otros lugares sin haber estado con anterioridad. Es manifiesto que uno de los mayores cambios acontecidos en la percepción de las ciudades es el acceso de información cartográfica en cualquier momento, en cualquier lugar y de cualquier lugar. 


\subsection{Análisis detallado de los elementos representados}

Existe un mayor número de elementos representados en 1993 frente a los mostrados en 2016. Es de suponer que parte de estos lugares aparecen testimonialmente en pocos mapas pues luego no son recogidos en el croquis sintético de la investigación.

Cuadro 2. Elementos estructurantes de la imagen urbana (1993-2016)

\begin{tabular}{|l|c|c|}
\hline & 1993 & 2016 \\
\hline Sendas & 66 & 39 \\
\hline Hitos & 54 & 41 \\
\hline Barrios & 17 & 19 \\
\hline Nodos & 8 & 12 \\
\hline Bordes & 5 & 5 \\
\hline
\end{tabular}

Elaboración propia

En 1993 aparecen más hitos que en 2016. Esto se debe a dos motivos fundamentalmente. Por un lado, la mayor focalización y nivel de detalle en las zonas centrales de la ciudad. Por otro, una cuestión de criterio en la organización de los elementos. Las infraestructuras de transporte en 2016 forman parte del grupo de nodos, mientras que en 1993 engrosaban la lista de hitos (Ej. estaciones). En 2016 se contabilizaron menos hitos y eso que en la actualidad aparecen nuevos elementos representados, inexistentes a comienzos de los noventa y que cambian significativamente la imagen de la ciudad. Los hitos del centro de la ciudad que forman la estructura central de la imagen se repiten en ambas fechas y permanecen en la imagen cognitiva representada. Destacan el parque de Abelardo Sanchez (81\%); el recinto ferial (73\%) y la Universidad (75\%). El sesgo de la muestra justifica alto valor del número de representaciones de la infraestructura educativa. Es el lugar común a todos los encuestados. Evidencia, que además de tratarse de un mapa perceptual individual, presenta patrones comunes y sociales. Las variaciones entre las dos fechas se encuentran en elementos tan importantes como el Hospital, que se señalaba en el 35,1\% entonces y el $61,3 \%$ en la actualidad; la catedral que ha pasado del $29,6 \%$ al $38,6 \%$ y el ayuntamiento con un aumento del $24 \%$ al 30,6\%. Mención especial merecen los centros comerciales. En 1993 solamente existía como tal el centro comercial «Los Llanos» cuya gran superficie dominante daba nombre popular al centro comercial. Aparecía en el 29,63\% de los casos. En la actualidad aparece en el 32\%. La función comercial de la ciudad ha crecido con la aparición de nuevas grandes superficies convirtiéndose en verdaderos referentes en la concepción de la ciudad. Los nuevos centros comerciales se distribuyen en los otros tres puntos cardinales de la ciudad. Se trata de los verdaderos organizadores de la imagen mental del siglo XXI y tienen mucho que ver con esa percepción holística de la ciudad. Las infraestructuras comerciales son determinantes en la imagen actual. Su función comercial y en muchos casos de ocio, las convierte en referentes para la población universitaria. La histórica función comercial de Albacete se refuerza hoy con estos nuevos lugares. El recinto ferial, origen de ese espíritu comercial permanece en el imaginario de la ciudad desde su construcción, hace ya más de tres siglos.

Los nodos son quizás los elementos puntuales que menos han cambiado al comparar ambas imágenes mentales. Junto a los límites, son los elementos que más permanecen en la imagen cognitiva. La plaza de Gabriel Lodares, la de Benjamín Palencia, el Altozano o el Sembrador se mantienen en la estructura mental un cuarto de siglo después. La estación de ferrocarril y la de autobuses 
son también claras reseñas de la ciudad a las que se añaden débilmente nuevas infraestructuras de comunicaciones como el aeropuerto. En 1993 se catalogaron como hitos, pero independientemente de su asignación a una u otra categoría, su significación sigue siendo muy elevada. Las comparaciones cuantitativas son complejas de asumir en estos estudios, pero se intuye que la importancia relativa de los nodos con respecto al resto de elementos de la ciudad era mayor en 1993 de lo que aparece en la imagen de 2016. Entre las ausencias más destacadas se encuentra la plaza Mayor, que en 1993 no se consignó y en 2016 no llega a suponer el 10\% de los nodos mostrados. Plaza que, aun manteniendo su histórico nombre, no logra incorporarse a la organización urbana como elemento significativo.

Las sendas son los elementos que organizan el mapa de mejor manera. En 1993 quedaba muy marcado el eje que comunicaba la Universidad con la zona de la estación de trenes y autobuses. Era quizás la conclusión más plausible de aquel estudio. El corredor formado por avenida de España, calle "Ancha», paseo de la Libertad y paseo de la Estación determinaba buena parte de la idea de ciudad (ver mapa 2). Una imagen de ciudad con forma de eje con elementos trasversales que se iban difuminando a medida que nos alejábamos de dicho tránsito. Hoy en día, este eje persiste en el ideario dentro de una concepción más global de ciudad. La calle Feria se muestra como contrapeso Este-Oeste al eje Norte-Sur. La circunvalación se ha convertido en un nuevo sostén articulador que construye una imagen sintética más global y completa de la ciudad. El objeto de estudio real se aproxima más al objeto de estudio percibido en 2016. Frente a la percepción de eje encontramos una imagen con forma de abanico cuyo tornillo se mantiene en la estación de autobuses y ferrocarril. Se irradia una ciudad en semicírculo reforzada por la antigua circunvalación con una visión de conjunto (Mapa 3).

En la imagen de la ciudad 2016 aparecen elementos nuevos como los accesos por carretera. Las carreteras son otras formas de acceder a la capital provincial además del transporte público como dejaba ver la imagen de 1993. El parque de vehículos y el acceso a los mismos por parte los estudiantes universitarios han aumentado de forma considerable en este cuarto de siglo. El crecimiento de los turismos en España ha tenido un valor medio del 60\%. Según este dato, se estima que la provincia de Albacete ha pasado de tener $107.998^{3}$ vehículos a tener 179.614 en 2015 . Se ha pasado de 3,23 personas por cada vehículo a tan sólo 2,18. El incremento de vehículos en la ciudad es manifiesto y constatable en los aparcamientos del campus en el periodo académico. La prevalencia de uso de uno u otro medio de transporte hace que la concepción de la ciudad varié. El espacio transitado de forma pedestre hace aumentar la capacidad de observación y comprensión de la ciudad obteniéndose más detalles (1993). El vehículo aumenta el radio de desplazamiento y la velocidad del mismo lo que hace incrementarse el ámbito de conocimiento de la ciudad, en detrimento del nivel de detalle (2016).

Los bordes son los elementos más estables y que más ha perdurado de todos los contemplados, a pesar incluso del notable crecimiento que ha experimentado la ciudad. Albacete es una ciudad compacta donde determinadas infraestructuras han marcado y marcan la ciudad. La vía del ferrocarril al norte de la ciudad y la circunvalación son vivo reflejo de ello. En 1993 el límite septentrional de la ciudad lo marcaba el parque lineal. Ocupó los terrenos dejados por el traslado de la vía del ferrocarril en 1967 a su actual emplazamiento, conformándose como parque en la década de los ochenta. Algunas percepciones de la ciudad no consideraban todavía todo el desarrollo urbanístico que supuso el desplazamiento hacia el norte de la ciudad de las vías del ferrocarril y

3. Número estimado para la provincia a partir del crecimiento medio a nivel nacional según datos del anuario de la Dirección General de Tráfico 2015. 
de la estación. Un grupo de mapas reflejaba el límite de la ciudad en la histórica posición de las vías del ferrocarril que durante más de un siglo les habían acompañado. Esta imagen ha variado sustancialmente. Hoy en día, el eje del parque lineal se considera un lugar plenamente integrado en la ciudad. A su vez aparece un refuerzo del límite de la ciudad al norte de la vía del ferrocarril con la nueva variante de la autovía A-31 que une el centro peninsular con el arco Mediterráneo meridional. En la otra parte de la ciudad se sitúa la primera circunvalación de la ciudad cuyo recorrido marcaba un claro límite a la percepción de la ciudad en 1993 reflejándose sólo el campus, el centro comercial y el campo de futbol. Los mapas actuales cuentan con más elementos representados en el exterior de dicha vía. En los últimos años se han llevado a cabo actuaciones para reducir esa barrera y cambiar su consideración de vía rápida e incorporarla como paseo con multitud de pasos para peatones y rotondas. Además, se está tratando de cerrar el anillo de la ciudad conectando ambos extremos a través del parque lineal.

La compacidad de la ciudad también es patente en acciones menos visibles para los ciudadanos como el planeamiento urbano. Albacete ha ido creciendo, en la mayoría de los casos, de una forma ordenada y compacta. Varios de los encuestados muestran en sus representaciones de la ciudad una línea imaginaria que simplifica y organiza el croquis presentado. En una cuarta parte de los mapas de 2016 aparece esa línea que completa exteriormente la circunvalación y en algún caso se une al ferrocarril y en otros a la autovía. Se trata de un nuevo e interesante elemento de análisis que no aparecía en 1993. En aquel entonces los límites representados fueron menores ya que muchos de los mapas tenían una perspectiva menos global.

El barrio es siempre el elemento más difícil de definir y de dibujar. En 1993 los barrios exteriores a la circunvalación no se mencionaban. El foco de los barrios se ponía en el centro de la ciudad, bien con la consideración de centro, bien con el nombre de Villacerrada o con la «zona» referida a las calles donde se concentran los lugares de ocio nocturno. Los barrios del resto de Albacete se reseñan de forma testimonial. En 2016 aparece un mayor crisol de respuestas. Éstas se concentran en los barrios de Centro, Ensanche y Carretas, pero también en barrios periféricos con cierta significación como San Pablo, San Pedro o San Antón. Ciertos barrios, considerados periféricos a comienzos de 1993, están completamente integrados en la percepción de la ciudad en 2016. Ejemplo manifiesto de ello es el barrio de Carretas. Ha cambiado la morfología y funcionalidad de un buen número de patios y naves, tal como refleja el levantamiento topográfico de 1992 a una morfología de viviendas y una función netamente residencial. Especial significación merece el barrio de la Milagrosa, más considerado como un límite o zona segregada que como formante de la ciudad. Se trata del barrio con las condiciones socioeconómicas más adversas de toda la ciudad. En 1993, no se mencionaba y en la actualidad se cita como barrio, pero no aparecen, calles, hitos o cualquier otro elemento que nos lleva pensar en su integración en el imaginario de la ciudad, más allá de conocerlo para evitarlo.

\subsection{Análisis comparado de las imágenes sintéticas}

El resultado del estudio concluye con la comparación visual de las imágenes sintéticas sobre la percepción de ambas fechas. Los datos disponibles de 1993 y los tabulados de 2016 se han incorporado a un SIG (mapa 2 y 3 ). 
Mapa 2. Percepción de la ciudad de Albacete 1993

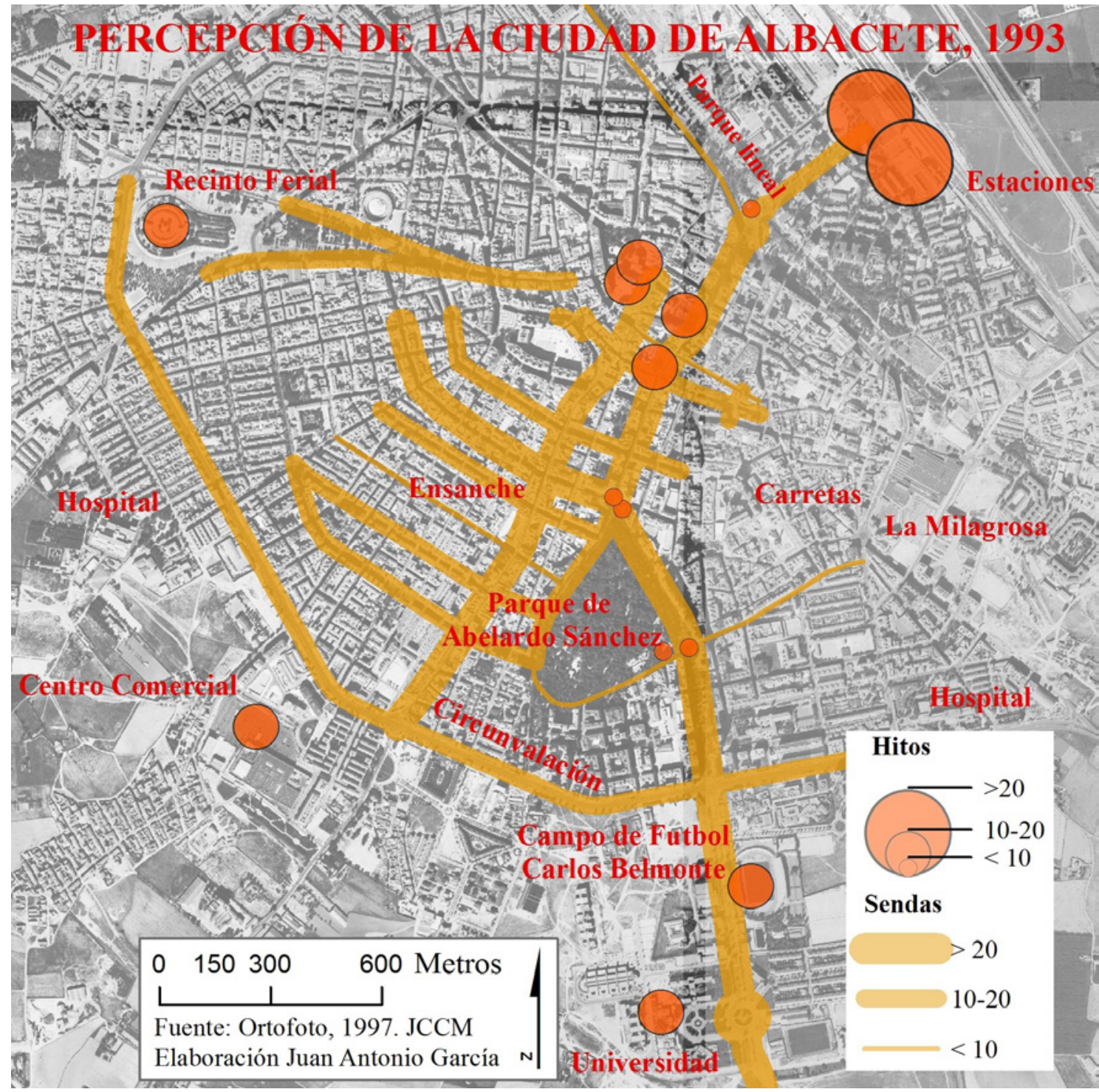

Elaboración propia

A partir de la combinación de puntos, líneas y polígonos se obtiene una visión esquemática representada sobre una base cartográfica precisa (Buzai, 2011). Se consigue la posibilidad de comparar dos informaciones bajo la misma herramienta. Se crea un modelo a caballo entre la cartografía geométrica y la perceptual, permitiendo una presentación de resultados mucho más intuitiva y visual. La mayoría de las representaciones, en ambas imágenes, se ubican entre los dos límites claramente marcados: la vía del ferrocarril y la circunvalación. Se repite el eje Norte-Sur desde la estación del ferrocarril hacia el campus universitario y en ambos, sale un ramal desde la plaza del Altozano hasta la Feria. La visualidad de la ciudad se establece en torno a esos dos ejes perpendiculares entre sí, que se sustentan por sus extremos a través del histórico recinto ferial, la estación de ferrocarril y la Universidad. Son también los elementos más representados en 2016 y verdaderos elementos icónicos y simbólicos de la morfología de la ciudad, pero también de su historia, dinamismo y evolución. Esos puntos de referencia son los pilares que construyen la representación de la ciudad a través de los ejes que los unen. También, son una parte importante de la explicación de lo que Albacete ha llegado a ser como ciudad. Se trata de lugares luminosos que perviven en la idea de ciudad de los estudiantes manchegos y probablemente de todos los albaceteños. 
Mapa 3. Percepción de la ciudad de Albacete, 2016

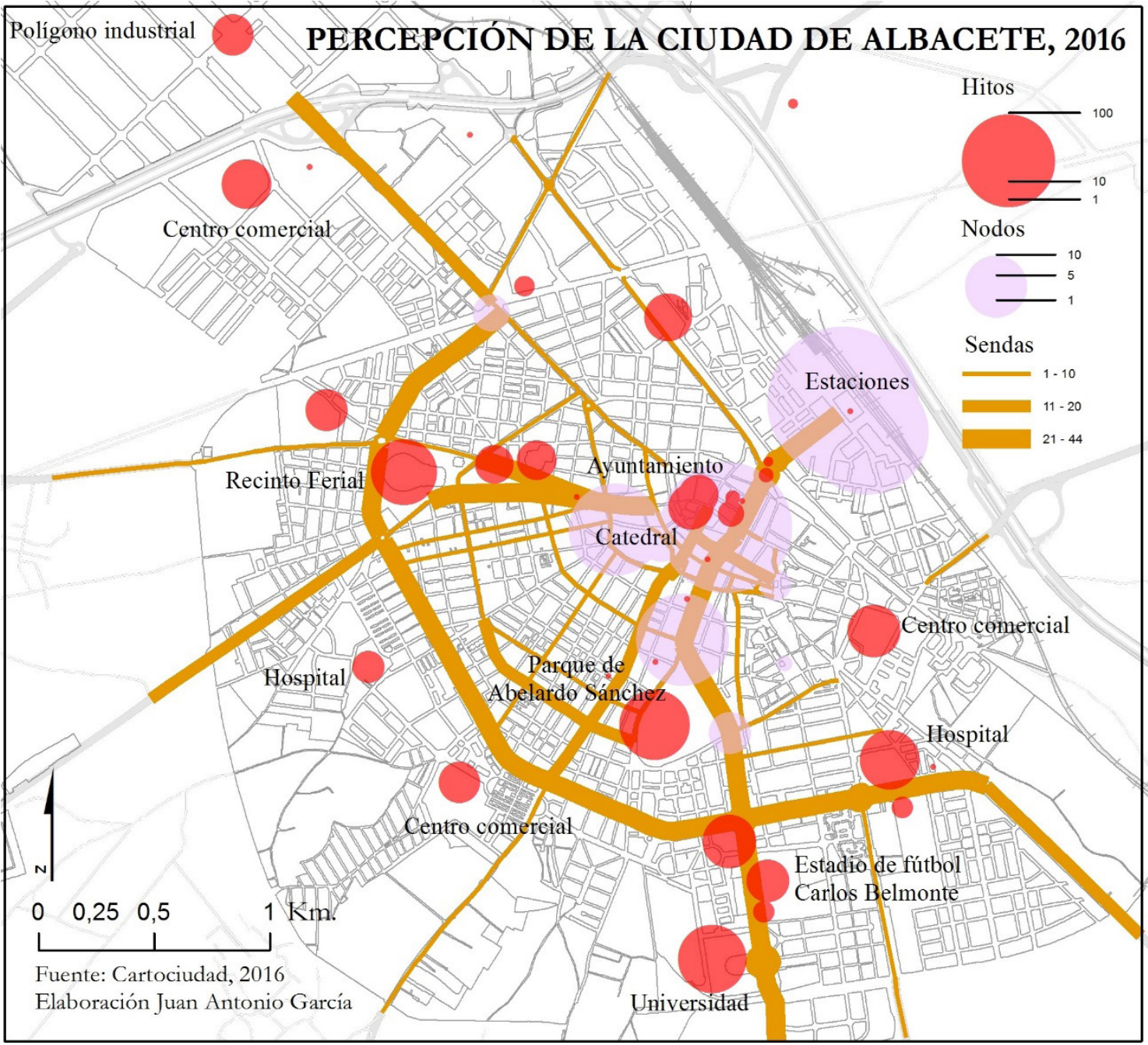

Elaboración propia

Es manifiesto el aumento de superficie representada por los estudiantes de 2016 en sus percepciones frente a los de 1993. En 2016 se mantienen, de forma destacada, estos elementos idiosincráticos de la ciudad y se añaden otros nuevos. Las nuevas incorporaciones se ubican más alejadas de la mancha conformada en 1993 y permiten ampliar la mancha cognitiva de la ciudad a nuevos barrios. Barrios que existían en 1993, pero que eran periféricos a lugares luminosos lo que hacía que permanecieran ocultos en el mapa mental. La mancha actual es una mancha más abierta, más metropolitana, que se organiza en torno a las vías de comunicación que dan acceso desde los cuatro puntos cardinales.

En el imaginario de los jóvenes estudiantes de 1993 aparecen por fuera de la circunvalación solamente el centro comercial «Los Llanos» de reciente creación y símbolo por aquel entonces de la modernidad comercial de la ciudad; la reciente Universidad de Castilla-La Mancha y el campo de futbol municipal cercano, situado en el camino entre el campus y el centro de la ciudad (ver mapa 4). Hoy aparecen nuevos lugares de ocio y compras repartidos por otros puntos de la ciudad. 
Mapa 4. Recorte de fotografía del levantamiento topográfico de 1992 Hoja I-11

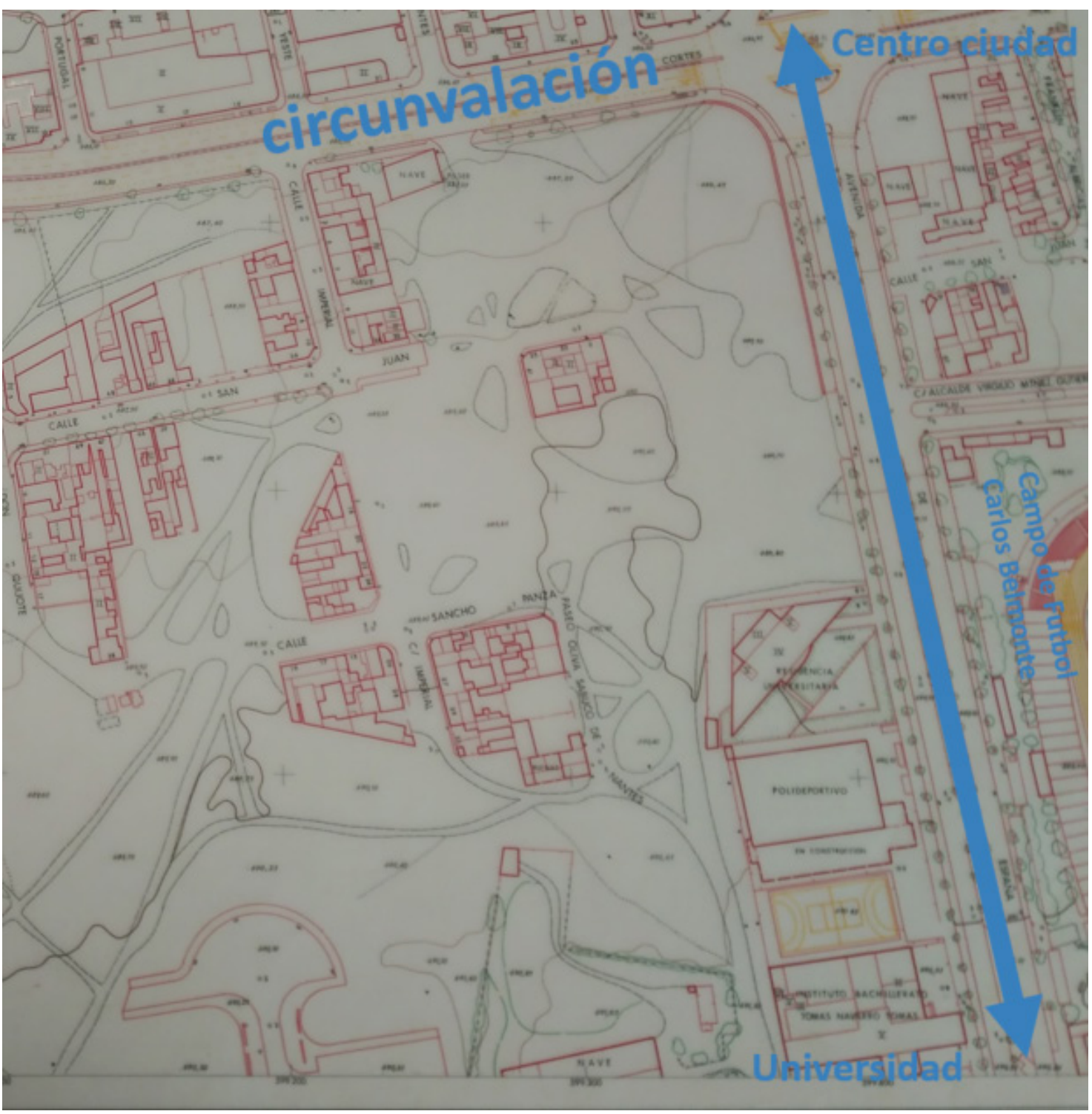

Elaboración propia

A su vez, son varios los lugares consolidados de la ciudad que no aparecen en la representación mental de 1993. Estos elementos si se visualizan en la imagen de la ciudad de 2016. Nos referimos, por citar unos ejemplos, a los dos centros hospitalarios de la ciudad; al polígono industrial de Campollano y a barriadas como Fátima, San Pedro o San Pablo. La ciudad sólo se percibe hasta la circunvalación. Además, por aquel entonces, la principal zona residencial de la ciudad era el denominado Ensanche. Así queda reflejado en la concepción de la ciudad de entonces. Esa imagen se ha debilitado en 2016. Puede deberse a dos cuestiones fundamentalmente. Por un lado, desde el inicio del estrenado siglo se ha producido un importante cambio en el perfil de los usuarios de esa zona. Muchas de esas viviendas son habitadas por inmigrantes. El barrio ha cambiado claramente su fisonomía, especialmente en la tipología de comercios que se sitúan en los bajos de las edificaciones. Por otro, son más las zonas representadas en los croquis, lo que puede llevar a mapas con un menor nivel de detalle. 


\section{Conclusiones}

El estudio muestra los significativos cambios acontecidos en la ciudad de Albacete en estos últimos 25 años. Aparecen variaciones en el tamaño y morfología de la ciudad, pero también en los comportamientos, hábitos y tipología de los estudiantes universitarios albaceteños. Esos cambios se reflejan en la idea que tienen de la ciudad. El acceso al vehículo privado, el incremento de centros comerciales, el aumento de acceso a la información georreferenciada y la posibilidad de ver mapas y comprender mejor el territorio, incluso en tiempo real, dibujan un nuevo mapa perceptual. La ciudad en 1993 era de menores dimensiones que en 2016, pero también era menor la idea y el conocimiento que se tenía de la misma. Había una mayor focalización frente a una visión más holística en 2016. Hoy en día se tiene una percepción más aproximada al tamaño real de la ciudad.

Las conclusiones obtenidas de esta investigación se sustentan con comparaciones que no pueden ir más allá de interpretaciones cualitativas que marcan tendencia. No puede ser de otra forma. Los datos se tomaron y trataron de forma semejante pero no exactamente igual. Además, fueron interpretados en otro momento, con diferente criterio y por diferentes personas. Sin embargo, arrojan reflexiones interesantes sobre los cambios en el conocimiento e interpretación de la ciudad. Dichos cambios van más allá de la edad, el género y la condición socioeconómica. Las relaciones del ciudadano con el territorio varían y están en continua evolución procediendo de la individualidad del lugar y del momento. Hay detalles de índole personal pero también social y de conjunto. Los cambios acontecidos en la sociedad en estos 25 años quedan reflejados en el cambio de percepción que se tiene de la ciudad. La concepción sobre la ciudad varía también con el crecimiento y cambios de la misma. La aparición de un elemento singular en un punto concreto hace variar la percepción de ese lugar, su centralidad y la aparición de las zonas aledañas que permanecían periféricas. Las reseñas de ese nuevo enclave lo dotan de una nueva visibilidad en esa cognición individual de la ciudad. La distribución periférica de los centros comerciales en estos 25 años ha generado una imagen más global de la ciudad.

La geografía de la percepción permite comparar el espacio objetivo con el subjetivo. La espacialización como técnica de análisis para comprender la ciudad aporta nuevas formas de integrar puntos, líneas y áreas a una estructura común. Se produce una vuelta a la georreferenciación geométrica de los elementos en su verdadera ubicación a partir de las topologías representadas en los croquis. Se puede entender como una forma más en el análisis de la percepción de la ciudad de una forma sintética. El análisis georreferenciado de los elementos de Lynch aporta una mayor visualidad y una posibilidad de comparación multitemporal sobre lugares comunes.

Se hace necesario seguir indagando en las construcciones mentales que hacen los ciudadanos del territorio y el aumento en la representación que hacen de él a partir de sus vivencias y sus experiencias. Otras conclusiones se pueden sustanciar en los siguientes aspectos.

- Hay una manifiesta dificultad de poder establecer comparaciones en términos absolutos debido a la complejidad de repetir con escrupulosa exactitud de la toma de datos.

- A pesar de esa limitación y no poder extraer conclusiones mesurables, si se establecen comparaciones relativas y tendencias ilustrativas que permiten ver el cambio en la relación de los ciudadanos con su ciudad y las formas y medios con los que interactúan.

- El estudio y la metodología empleada se muestran como herramientas consistentes en el análisis de ciudades medias con una escala accesible al ciudadano. 
- Es clara la influencia de la democratización de la cartografía en la forma de hacer los croquis, el área representada y el nivel de detalle.

- El crecimiento de la ciudad genera nuevos elementos significativos en la misma, bien por su cambio de condición, bien de nueva aparición que establecen nuevas relaciones.

- Reafirmamos el valor de los mapas cognitivos y la necesidad de sistematizar y estructurar la metodología y el corpus científico de esta corriente geográfica que pueda dar una perspectiva complementaria, cualitativa, subjetiva y humanista a la comprensión del territorio.

Todas estas conclusiones animan a abrir una línea de trabajo y tratar de recuperar los estudios desarrollados sobre geografía de la percepción en el último cuarto de siglo en diferentes ciudades españolas. Se sugiere continuar corroborando las conclusiones extraídas en este estudio e incluso ver posibles cambios de la sociedad española en diferentes contextos a través de su percepción de la ciudad. La puesta en valor de trabajos pasados sobre geografía de la percepción, a través de estudios multitemporales, puede ofrecer una visión diferente de los cambios sociales de los ciudadanos respecto a su ciudad.

\section{Referencias bibliográficas}

- Aguiló, Alonso, M. (1999). El paisaje construido: una aproximación a la idea de lugar. Colegio de Ingenieros de Caminos, Canales y Puertos.

- Andrés López, Gonzalo. (2008) «Geografía y ciudades medias en España: ¿a la búsqueda de una definición innecesaria?» Scripta Nova: revista electrónica de geografía y ciencias sociales.12. http://www.ub.es/geocrit/sn/sn-270/ sn-270-49.htm [Fecha de consulta 3 de mayo de 2018]

- Appleyard, Donald (1976). Planning a pluralist city: Conflicting realities in Ciudad Guayana. MIT Press Cambridge, MA.

- Aragonés, Juan I. (1988). Mapas cognitivos: una revisión bibliográfica. Anales de Geografía de la Universidad Complutense, $\mathrm{N}^{\circ} 8,1988$, págs. 155-166 https://dialnet.unirioja.es/servlet/articulo?codigo=2138677 [Fecha de consulta 3 de mayo de 2018]

- Bailly, Antoine S. (1989) Lo Imaginario Espacial y la Geografía. Anales de geografía de la Universidad Complutense, ISSN 0211-9803, No 9, 1989, págs. 11-20 http://revistas.ucm.es/index.php/AGUC/article/view/AGUC8989110011A [Fecha de consulta 3 de mayo de 2018]

- Boira i Maiques, Josep Vicent, Souto González, Xosé Manuel y Reques Velasco, Pedro. 1994. Espacio Subjetivo y Geografía: Orientación teórica y praxis didáctica. Nau Llibres.

- Boira i Maiques, Josep Vicent (1992). «El estudio del espacio subjetivo (geografía de la percepción y del comportamiento): una contribución al estado de la cuestión.» En Estudios geográficos 53.209: 573-92

- Bosque Maurel, Joaquín (1991). Atlas social de la ciudad de Granada.

- Bosque Sendra, J., De Castro Aguirre, C., Díaz Muñoz, M.A. and Escobar Martínez, F.J., (1992). Prácticas de geografía de la percepción y de la actividad cotidiana. Barcelona, Ed. OIKOS-TAU.

- Burriel, Eugenio. (2008). «La década prodigiosa del urbanismo español» (1997-2006). Scripta Nova, 12(270), 64. http://www.ub.edu/geocrit/-xcol/383.htm [Fecha de consulta 3 de mayo de 2018]

- Buzai, Gustavo D. (2011). «La Construcción de mapas mentales mediante apoyo geoinformático. Desde Las Imágenes Perceptivas Hacia La Modelización Digital.» Revista Geográfica de Valparaíso 44:1-17.

- Capel, Horacio. (1973) «Percepción del medio y comportamiento geográfico.» Revista de geografía 7.1-2: 58-150. http://www.raco.cat/index.php/RevistaGeografia/article/viewFile/45873/56665\&a=bi\&pagenumber $=1 \& w=100$ [Fecha de consulta 3 de mayo de 2018]

- Carreiras, Manuel (1986) Mapas cognitivos: Revisión crítica. Estudios de psicología, 7, 59-91.

- De Castro Aguirre, Constancio de y Bosque Sendra, Joaquín (1993) «Mapas mentales de la España autonómica: La preferencia residencial». Estudios geográficos, 54, 181-208.

- De Castro Aguirre, Constancio (1997). «La búsqueda de datos para mapas cognitivos: Guía psicológica para geógrafos». Anales de geografía de la Universidad Complutense. 
- De Castro Aguirre, Constancio (1999). «Mapas Cognitivos. Qué son y cómo explorarlos.» Scripta Nova: revista electrónica de geografía y ciencias sociales 3. http://www.raco.cat/index.php/scriptanova/article/view/55308 [Fecha de consulta 3 de mayo de 2018]

- Dollfus, Olivier. (1978) El análisis geográfico. Oikos Tau

- Ellard, C. (2016). Psicogeografía. La influencia de los lugares en la mente y el corazón: Barcelona: Ariel.

- Estébanez Álvarez, José. (1979) «Consideraciones sobre la geografía de la percepción. En Paralelo 37, 5-22.

- Estébanez Álvarez, José 1981. «Problemas de interpretación y valoración de los mapas mentales». En Anales de Geografía de la Universidad Complutense, 15.

- Escobar Martínez, Francisco Javier (1991). «Encuestas de percepción: la población mayor en Alcalá de Henares. Experiencias a partir de un trabajo de campo». Serie geográfica (1), 53-75.

- Fernández Gutiérrez, Fernando y Asenjo Pelegrina, Rafael (1998). La visión subjetiva del espacio urbano almeriense.

- Fernández Santamaría, Francisco y García Martínez, Carmen (1993). «Los mapas mentales como fuente de información sobre la imagen urbana: una aplicación práctica». Ensayos: Revista de la Facultad de Educación de Albacete (8), 45-58.

- García Ballesteros, Aurora y Bosque Sendra, Joaquín (1989) El Espacio Subjetivo de Segovia. Madrid: Editorial Universidad Complutense.

- García Monteagudo, Diego (2015). Las percepciones sociales en el barrio de Ruzafa (Valencia): una aplicación didáctica. M.A. de la Riva, J., Ibarra, P., Montorio, R., Rodrigues, M. (Eds.) Análisis espacial y representación geográfica: innovación y aplicación: 1395-1404 Universidad de Zaragoza-AGE.

- Gieseking, Jack Jen (2013) «Where we go from here: The mental sketch mapping method and its analytic components». Qualitative Inquiry, 19, 712-724.

- Gould, Peter; White, Rodney. (1974). Mental maps (Harmondsworth). England, and New York: Penguin.

- Hernández, Nelcy Azucena (2009). «El Premapa para el análisis Geográfico.» Revista de Estudios Urbanos, Regionales, Territoriales, Ambientales y Sociales, 142. http://uptc.metarevistas.org/index.php/perspectiva/article/ view/1711 [Fecha de consulta 3 de mayo de 2018]

- López Trigal, Lorenzo (2016). «Las pequeñas ciudades y aglomeraciones ibéricas: identificación, dinámicas y estrategias». Ciudad y territorio: Estudios territoriales (187), 25-42.

- Lynch, Kevin (1960). The image of the city MIT press.

- Lynch, Kevin (1981). La buena forma de la Ciudad, Edit. Gili. Barcelona.

- Lowenthal, David (1961) «Geography, Experience, and Imagination: towards a geographical epistemology». Annals of the association of American geographers, 51, 241-260.

- Moore, Gary. T. y Golledge, Reginald G. (1976). Environmental knowing: Theories, research and methods. Dowden.

- Morales Yago, Francisco José (2012) «La geografía de la percepción: una metodología válida aplicada al caso de una ciudad de tipo medio-pequeño. El ejemplo de Yecla (Murcia)». Papeles de Geografía, 137-152. http://revistas. um.es/geografia/article/view/176261 [Fecha de consulta 3 de mayo de 2018]

- Morales Yago, Francisco José (2015) «La ciudad de Valencia como espacio percibido por los estudiantes universitarios. Aportaciones desde el análisis propuesto por la geografía de la percepción». Estudios Geográficos, 76, 203-233. http://estudiosgeograficos.revistas.csic.es/index.php/estudiosgeograficos/article/view/449 [Fecha de consulta 3 de mayo de 2018]

- Muñoz Espinosa, Elena María y Rodriguez Domenech, María Ángeles (2015) «Enseñar y aprender a pensar los paisajes urbanos. La percepción urbana en las ciudades». M.A. de la Riva, J., Ibarra, P., Montorio, R., Rodrigues, M. (Eds.) Análisis espacial y representación geográfica: innovación y aplicación: 1153-1161 Universidad de Zaragoza-AGE. http://congresoage.unizar.es/eBook/trabajos/121_Mu\%C3\%B1oz\%20Espinosa.pdf [Fecha de consulta 3 de mayo de 2018]

- O'Reilly, Tim. (2005). What is Web 2.0? http://oreilly.com/web2/archive/what-is-web-20.html?page=1 [Fecha de consulta 3 de mayo de 2018]

- Pocock, Douglas and Hudson, Ray. (1978): Images of the urban environment. New York, Columbia University Press.

- Reques Velasco, Pedro (2006) «La Geografía de la Percepción y del comportamiento: una introducción». V Jornadas Nacionales de Investigación en Psicología, Santander. 
- Reques Velasco, Pedro (1992): «Balance crítico de dos décadas de geografía de la percepción en España. A propósito de los estudios sobre espacios urbanos». Actas del V coloquio de Geografía cuantitativa. Universidad de Zaragoza, 341-356.

- Roth, R. E. (2013) «Interactive maps: What we know and what we need to know». Journal of Spatial Information Science. Number 6, pp. 59-115.

- Somoza Medina, José (1995) La geografía de la percepción como instrumento de ayuda al planeamiento urbano. Un posible ejemplo en la ciudad de Ourense.

- Souto González, Xosé Manuel y Boira i Maiques, Josep Vicent (1995) «Percepción del medio y planificación del territorio: el caso de Vigo». Boletín de la Asociación de Geógrafos Españoles, 67-80. https://dialnet.unirioja.es/servlet/articulo?codigo=1318481 [Fecha de consulta 3 de mayo de 2018]

- Tuan, Yi Fu 1974. Topofilia. Un estudio sobre percepciones, actitudes y valores medioambientales. Melusina, Madrid. http://www.melusina.com/rcs_gene/topofilia.pdf [Fecha de consulta 3 de mayo de 2018]

- Vara Muñoz, José Luis (2008) «Cinco décadas de Geografía de la percepción». Ería, 371-384. https://dialnet.unirioja.es/descarga/articulo/2927235.pdf [Fecha de consulta 3 de mayo de 2018]

- Vara Muñoz, José Luis. (2010) «Análisis De Textos En Geografía de la Percepción: Estado de la cuestión y bases conceptuales.» Baética: Estudios de arte, geografía e historia.32: 127-46.

- Vara Muñoz, José Luis. (2010b): «Un Análisis Necesario: Epistemología De La Geografía De La Percepción.» Papeles de geografía. 51-52 337-344 https://digitum.um.es/jspui/bitstream/10201/15411/1/31-VARA\%20 MU\%C3\%91OZ\%20337-344.pdf [Fecha de consulta 3 de mayo de 2018]

- Villena Martínez, María Magdalena (2012): «Percepción y espacio urbano: El comportamiento de los habitantes del barrio María Auxiliadora de Novelda (Alicante)». En GeoGraphos, Revista Digital para Estudiantes de Geografía y Ciencias Sociales. Vol. 3, n. 29, pp. 1-15. Disponible en: http://web.ua.es/revista-geographos-giecryal [Fecha de consulta 3 de mayo de 2018]

- Zárate, Antonio; Vázquez Márquez, Alfonso; Candelas Conde, María; Lorente Toledo, Enrique y Blanco, Juan A. (1985) «Una aproximación a la geografía de la Percepción». Didáctica geográfica, 43-64.

\section{Sobre el autor}

Juan Antonio García González

Profesor de la Facultad de Humanidades de Albacete y miembro del departamento de Geografía y Ordenación del Territorio de la Universidad de Castilla la Mancha. Su actividad investigadora se desarrolla fundamentalmente en dos entornos: estudios urbanos y turismo en espacios de interior. En ambos casos, la cartografía temática, como forma de análisis y presentación de resultados, es un elemento central en sus estudios. Son múltiples las publicaciones en libros, revistas científicas y actas de congresos nacionales e internacionales, donde los mapas y sus múltiples posibilidades son el componente vehicular de sus investigaciones. 